\section{CHILDREN ENCOURAGED TO UPCYCLE}

GlaxoSmithKline, makers of oral care brand Aquafresh, have teamed up with upcycling company TerraCycle UK to launch the Aquafresh oral care Brigade, a recycling fundraiser which encourages schools to collect used toothbrushes and toothpaste tubes to be recycled and upcycled into everyday products (the products are currently under development and are not for sale).

For every product brought in for recycling, $2 p$ will be donated to a charity of the school's choice. The scheme teaches children about resource conservation whilst reinforcing good dental hygiene through educational materials on brushing for kids.

The scheme works well with the interactive oral care education programme 'Brushing Buddies' launched by the Aquafresh team last year. Brushing Buddies is designed for children aged 3-6 and fulfils key elements of the ECM (Every Child Matters) agenda, including health and wellbeing, with the express intention of delivering improved oral care outcomes for children.

Teachers can combine the Brushing Buddies programme with the Aquafresh oral care Brigade scheme to help pupils learn about oral care and take ownership of their tooth brushing, whilst at the same time helping to raise money for their school, group or charity.

The Aquafresh oral care Brigade is open to primary schools and youth groups such as scout and guiding across the UK who can get involved by signing up at www.terracycle.co.uk. Reader response number 63

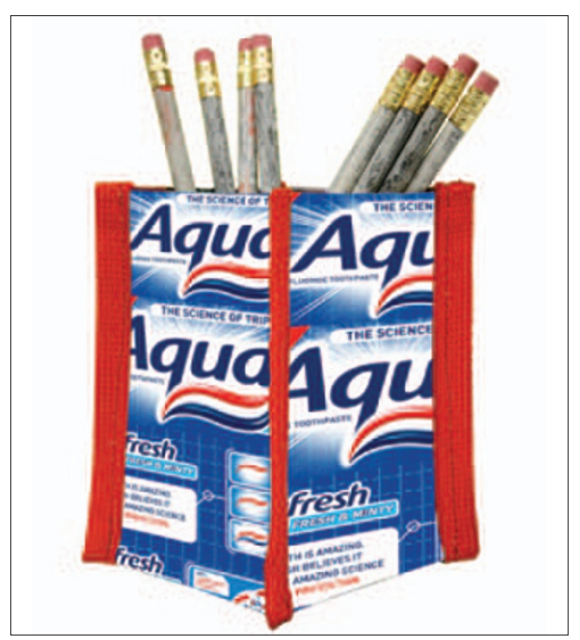

\section{BRIDGE THEORY WITH REALITY}

The Dentistry Business is currently preparing for a new intake of students for its next university-accredited programme for dentists and practice managers starting in October.

The Level 7 Postgraduate Certificate in Dental Practice Management is the perfect bridge between the theory and the day-to-day realities of practice management. Its academic requirements make it suitable for experienced practice managers who have a level 4 or 5 qualification.

For dentists embarking on the FGDP Career Pathway, it fulfils all the requirements necessary to com- plete the management component. It also provides a further 30 credits in the 'other' section of the Pathway, providing dentists with a total of 60 credits towards Fellowship.

Practice managers without a university-accredited qualification can also benefit from The Dentistry Business' Level 4 Certificate in Practice Management, which provides a recognised, transferable university qualification.

The 9-day modular programmes run over a 12-month period, combining exercises, case studies and direct experience to enable participants to exchange knowledge and learn from each other's success.

Reader response number 64

\section{DEDICATED GREEN FINANCE SCHEME}

New analysis from the Carbon Trust and Siemens has shown that the estimated market for energy-efficient equipment finance over the next three years in the Professional Services sector is £270 million. However, businesses remain cautious about investing in equipment upgrades in a slowly recovering economy. In order to make such investment affordable, the Carbon Trust and Siemens have launched a new scheme to provide UK professional services businesses with green equipment finance. This major new scheme will boost green growth and unlock business investment in the low carbon economy key to economic recovery.

Enabling investment in such technologies as low energy lighting, energy-efficient motors, low carbon air conditioning or biomass heating, the new dedicated green finance scheme is a first and will enable professional services businesses to invest in equipment which not only saves energy costs, but also often helps improve productivity.

Any business is able to apply for new green growth finance from the scheme, which is designed to match monthly payments with the equivalent savings from lower energy consumption. The Carbon Trust will apply its expertise in carbon saving from energy-efficient technologies to provide a reliable and trusted assessment of the carbon, energy and cost savings of any application for finance. Siemens Financial Services Ltd. in the UK (SFS UK) provides the financial backing and manages the provision of funding.

Reader response number 65

\section{LASERS FOR LESS THIS SUMMER}

The PowerPen 4w Quicklase cordless laser is currently available at a special summer price of $£ 1,750$. It has two customisable pre-sets (one for sterilisation, perio and endo and a second for cutting with auto power), is cordless, easy to use and cuts well with built-in fibre calibration and a long life fast-charge battery.

In addition, Quicklase have launched the new PowerDesktop
Picasso 7 laser at a special price of $£ 3,500$. The new PowerDesktop has a 7 watts $810 \mathrm{~nm}$ diode power with eight customisable pre-sets, a builtin fibre caddy, a touch screen with a choice of multiple languages, an adjustable aiming beam and adjustable pulse/continuous mode, making it the most versatile laser to use.

Prices include delivery and online training.

Reader response number 66 